\title{
Gas Chromatography-Mass Spectroscopy Analysis and Chemical Composition of Ngaoundere, Cameroon Honey
}

\author{
Cheh Auguistine Awasum ${ }^{1}$, Sandra Leila Monkam Fotzo ${ }^{2}$, Julius Awah Ndukum², \\ ChintemWilliams Denbon Genesis ${ }^{3,}$, Andre Zoli ${ }^{2}$ \\ ${ }^{1}$ Departmentof Veterinary Surgery and Radiology, Ahmadu Bello University, Zaria, Nigeria \\ ${ }^{2}$ School of Veterinary Medicine and Sciences, University of Ngaoundere, Ngaoundere, Cameroon \\ ${ }^{3}$ Department of Biochemistry, Ahmadu Bello University, Zaria, Nigeria
}

\section{Email address:}

awasumca@yahoo.com (C. A. Awasum), lielafotzo@yahoo.com (S. L. M. Fotzo), juliusawahndukum@yahoo.co,uk (J. A. Ndukum), williamschintemdg@gmail.com (C.W. D. Genesis), re.zili@yahoo.fr (A. Zoli)

\section{To cite this article:}

Cheh Auguistine Awasum, Sandra Leila Monkam Fotzo, Julius Awah Ndukum, Chintem Williams Denbon Genesis, Andre Zoli. Gas Chromatography-Mass Spectroscopy Analysis and Chemical Composition of Ngaoundere, Cameroon Honey. American Journal of Bioscience and Bioengineering. Vol. 3, No. 5, 2015, pp. 33-36. doi: 10.11648/j.bio.20150305.11

\begin{abstract}
The investigation was carried out to determine the possible chemical components and quantity of the component present in honey using GC-MS analysis. Traditionally the natural honey are used in the treatment of ulcers, wound healing, swells, asthma, cough, hyperacidity, leprosy, diuretic, antimicrobial, jaundice, diuretic activity, hypolipidemic effect, hepatoprotective activity and fever. In the present study, the honey has been subjected to GC-MS analysis. Fourteen chemical constituents have been identified, the major chemical constituents are 2, 4-Dimethyl-1-pentanol (9.23\%), 3, 5-Dihydroxy-6-methyl-2, 3-dihydro-4H-pyran-4-one (8.91\%), 2-Furancarboxaldehyde, 5-hydroxymethyl (36.02\%), 2-Butoxyethyl acetate (11.11\%). It could be concluded that the Ngaoundere, Cameroon honey contains various bioactive compounds.
\end{abstract}

Keywords: GC-MS Analysis, Ulcer, Chemical Component, Honey

\section{Introduction}

Honey is a natural product obtained from bee and it is widely sought due to its unique nutritional and medicinal properties, which are attributed to the influence of the different groups of substances it contains. Codex Alimentarius Commission defined honey as the natural sweet substance produced by honey bees, Apismellifera, from the nectar of plants or from the secretions of living parts of plants or excretions of plant sucking insects on the living parts of plants, which honey bees collect, transform by combining with specific substances of their own, deposit, dehydrate, store and leave in the honey comb to ripen and mature $[1,2]$. The bees are said to produce honey in order to serve as their source of food in times of scarcity or during harsh weather conditions [3].

Basically, natural honey is a sticky and viscous solution which contents carbohydrate (mainly glucose and fructose), water, protein, ash and minor quantities of amino acids, enzymes and vitamins as well as other substances like phenolic antioxidants [3-7]. Each of these minor constituents is known to have distinctive nutritional or medicinal properties and different applications of natural honeys [3]. Although the major constituents of honey are nearly the same in all honey samples, the precise chemical composition and physical properties of natural honeys differ according to the plant species on which the bees forage [3, 8-11]. Furthermore, differences in climatic conditions and vegetation are important factors that can affect the various properties of honey.

Honey is used for nutritional, medicinal and industrial purposes and it is an important commodity in the international market; serving as foreign exchange earner for many countries. Beekeeping is an age old tradition in Cameroon as in Nigeria but it is not considered as a profit making venture in most parts of the country $[12,13]$, honey production has largely been at a subsistence level [14]. However, honey is found in beehives in large quantities in Nigeria [15] and it has been recognized that honey production (beekeeping) has the potential to develop as a 
prime agro-horticultural and forest-based industry which can well become a major foreign exchange earner if international standards are met. For instance, it was shown that in Adamawa State, a beekeeper with an average number of 27 beehives made an average of $\$ 1,119.29$ per annum from the sales of honey and beeswax $[16,17]$. Similarly, it was reported that in Ngaoundere (Ngaounda) in northern part of Cameroon, beekeepers with an average of 20 beehives made average revenue from sales of honey, bees wax and propolis amounting to about $\$ 2,148.42$ per annum and $\$ 1,027.29$ per annum for langstroth and top bar hives users, respectively $[18,19]$ had reported that in Adamawa State, only a small percentage (5.62\%) of the farming population who were already in the practice of beekeeping actually perceived apiculture as a profitable enterprise and know of its profitability; majority $(56.25 \%)$ of the rural farming community and about $36.25 \%$ of the urban farming community considered apiculture only as a sideline economic activity. The ecology of Cameroon like Nigeria varies from tropical forest in the south to dry savanna in the far north, yielding a diverse mix of plant and animal life. Available literature on the properties and qualities of Nigerian honey have largely focused on samples obtained in the southern parts of the country $[19,20,21]$; with very scarce information on samples obtained in the northern parts, especially the northeast sub-region where commercial beekeeping practice has been documented [17, 19]. These practices are similar to what is obtained in the northwest of Cameroon and the Adamawa region of Cameroon is a neighbor to the Adamawa State of Nigeria. Several Health Benefits has been attributed to honey viz: Honey contains flavonoids, antioxidants which help reduce the risk of cancers and heart disease, Recent research shows that honey treatment may help disorders such as ulcers, it has antibacterial, because the bees add an enzyme that makes hydrogen peroxide," said Peter Molan, director of the Honey Research Unit at the University of Waikato in New Zealand., it also Increase athletic performance, Honey helps with coughs particularly buckwheat honey. In a study of 110 children, a single dose of buckwheat honey was just as effective as a single dose of dextromethorphan in relieving nocturnal cough and allowing proper sleep.

This paper reports on the biochemical properties of honey from the northwest of Cameroon Africa.

\section{Materials and Method}

\subsection{Collection and Preparation of the Honey Samples}

The honey was harvested from Ngaoundere in the Adamawa region of Cameroon and used for the study. The sample was collected freshly in sterile containers (labeled with numbers, place and date of collection) and stored at ambient temperature until analyzed. Unwanted material such as wax sticks, dead bees and particles of combs were removed by straining the samples through cheesecloth before analysis.

\subsection{GC-MS Analysis}

\subsubsection{Instruments and Chromatographic Conditions}

For the identification of phytoconstituents in honey was carried out by subjecting the sample to GC-MS analysis. The sample $(2 \mu \mathrm{l})$ was injected into a RTX-5 column (60 m X 0.25 $\mathrm{mm}$ i.d., film thickness $0.25 \mu \mathrm{m}$ ) of GC-MS (model GC-MS-QP-2010 plus, Shimadzu Make). Helium was used as a carrier gas at a constant column flow $1.2 \mathrm{ml} / \mathrm{min}$ at $173 \mathrm{kpa}$ inlet pressures. Temperature programming was maintained from $100^{\circ} \mathrm{C}$ to $200{ }^{\circ} \mathrm{C}$ with constant rise of $5^{\circ} \mathrm{C} / \mathrm{min}$ and then held isothermal at $200{ }^{\circ} \mathrm{C}$ for $6 \mathrm{~min}$; further the temperature was increased by $10{ }^{\circ} \mathrm{C} / \mathrm{min}$ up to $290{ }^{\circ} \mathrm{C}$ and again held isothermal at $290{ }^{\circ} \mathrm{C}$ for $10 \mathrm{~min}$. The injector and ion source temperatures were $270{ }^{\circ} \mathrm{C}$ and $250{ }^{\circ} \mathrm{C}$, respectively. The wax was dissolve in methanol (HPLC grade) injected with a split ratio of $1: 10$. Mass spectra were taken at $70 \mathrm{eV}$; a scan interval of $0.5 \mathrm{~s}$ and fragments from 40 to 950 Dalton.

\subsubsection{Identification of Components}

Interpretation on mass spectrum of GC-MS was done using the database of National Institute Standard and Technology (NIST) having more than 62,000 patterns. The mass spectrum of the unknown component was compared with the spectrum of the known components stored in the NIST library. The name, molecular weight and structure of the components of the test materials were ascertained.

\section{Result and Discussion}

\section{GC-MS analysis}

GC-MS chromatogram of honey in Figure 1 indicates the presences of fourteen phytochemical constituents. On comparison of the mass spectra of the constituents with the NIST library 2005, the fourteen phytoconstituents were characterized and identified (Table 1). The various phytochemicals which contribute to the medicinal activity of honey are natural in nature. Traditionally, the natural honey are used in the treatment of ulcers, wound healing, swells, asthma, cough, hyperacidity, leprosy, diuretic, antimicrobial, jaundice, diuretic activity, hypolipidemic effect, hepatoprotective activity and fever. The GC-MS analysis identified the following major chemical constituents namely 2 , 4-Dimethyl-1-pentanol, 3, 5-Dihydroxy-6- methyl-2, 3dihydro-4H-pyran-4-one, 2-Furancarboxaldehyde 5-hydrox methyl, 2-Butoxyethyl acetate. These compounds are known to have some biological activity such as antibacterial, antifungal, antioxidant and wound healing power activity as previously reported. Also a study showed that $100 \%$ inhibition was observed on $\mathrm{MH}$ agar with honey in Pseudomonas aeruginosa, eoagulase-positive Staphylococcus, Proteus mirabilis, and Citrobacter diversus, Klebsiella pneumonia at $25 \%$ concentration $(\mathrm{v} / \mathrm{v})$ honey concentration. The activity found in the previous works could be attributed to the presence of this secondary metabolite identified from honey and bee wax [16].

Although 2-Furancarboxaldehyde, 5-hydroxymethyl (FCHM) the most abundant chemical constituent is not yet 
been ascertained as a harmful substance however, its content in honey are imposed in many countries. This is to guard against distribution of honey of low quality. FCHM is an indication of overheating, storage at elevated temperature or an aged sample or adulterated with invert sugars $(20,21)$. The presence of various bioactive compounds justifies the use of the whole plant for various ailments by traditional practitioners.

Furthermore, the geographical origin of honey is a relevant factor that can influence its different composition. The accumulation of phytochemicals such as (carbohydrates, phenolic compounds and volatile compounds) is dependent on climatic conditions (sunlight, moisture), soil characteristics and other factors; therefore, it is reasonable to believe that differences between honeys obtained from different countries are bound to be different due to the compositions of pollen or nectar, which have the greatest influence on the chemical composition [22, 23].

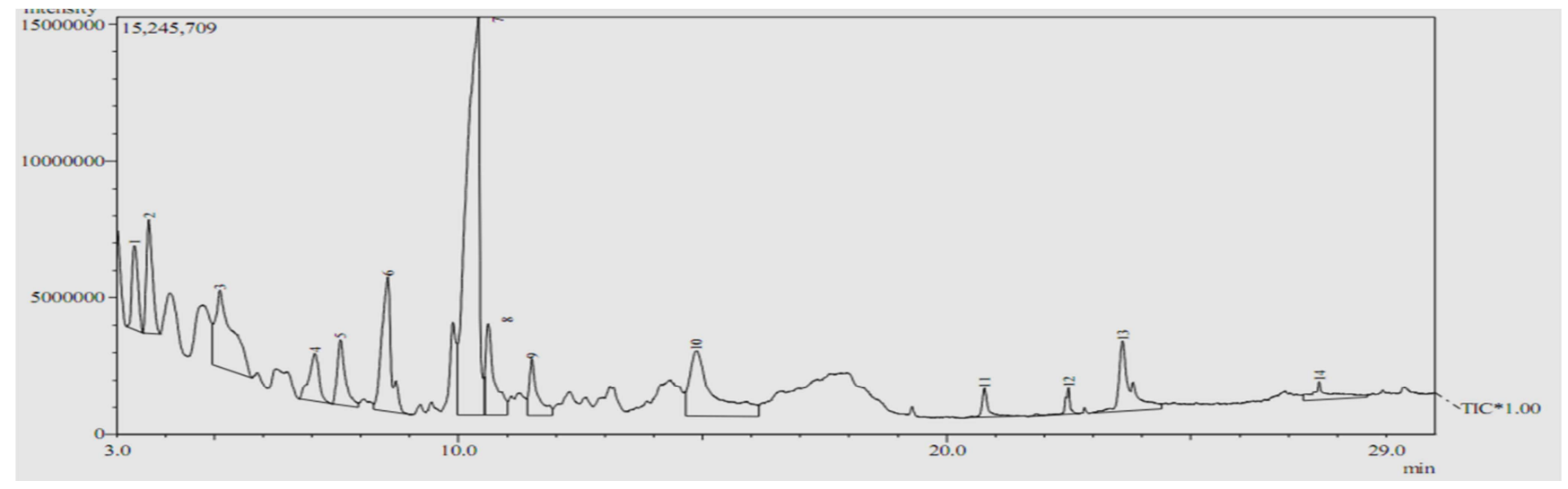

Figure 1. GC-MS Chromatogram of honey wax.

Table 1. Phytocomponents identified in the honey by GC-MS.

\begin{tabular}{|c|c|c|c|c|c|c|}
\hline PN & RT & Name of the compound & Mol. Form & P.A. \% & SI (\%) & MW \\
\hline 1 & 3.36 & 2-Furancarboxaldehyde & $\mathrm{C}_{5} \mathrm{H}_{4} \mathrm{O}_{2}$ & 3.56 & 94 & 96 \\
\hline 2 & 3.66 & alpha.-Furfuryl alcohol & $\mathrm{C}_{5} \mathrm{H}_{6} \mathrm{O}_{2}$ & 4.87 & 90 & 98 \\
\hline 3 & 5.12 & 2,4-Dimethyl-1-pentanol & $\mathrm{C}_{7} \mathrm{H}_{16} \mathrm{O}$ & 9.23 & 77 & 116 \\
\hline 4 & 7.06 & 2,5-Dimethyl-4-hydroxy-3(2H)-furanone & $\mathrm{C} 6 \mathrm{H} 8 \mathrm{O} 3$ & 3.44 & 87 & 128 \\
\hline 5 & 7.59 & Methyl 1-methylcyclopropyl ketone & $\mathrm{C}_{6} \mathrm{H}_{10} \mathrm{O}$ & 3.70 & 86 & 98 \\
\hline 6 & 8.56 & 3,5-Dihydroxy-6-methyl-2,3dihydro-4H-pyran-4-one & $\mathrm{C}_{6} \mathrm{H}_{8} \mathrm{O}_{4}$ & 8.91 & 91 & 144 \\
\hline 8 & 10.62 & 2-Hexanone, 3-methyl-4-methylene & $\mathrm{C}_{8} \mathrm{H}_{14} \mathrm{O}$ & 5.68 & 83 & 126 \\
\hline 9 & 11.51 & 2H-Imidazol-2-one, 1,3-dihydro-4-methyl & $\mathrm{C}_{4} \mathrm{H}_{6} \mathrm{~N}_{2} \mathrm{O}$ & 3.31 & 80 & 98 \\
\hline 10 & 14.90 & 2-Butoxyethyl acetate & $\mathrm{C}_{8} \mathrm{H}_{16} \mathrm{O}_{3}$ & 11.11 & 80 & 160 \\
\hline 11 & 20.82 & n-Hexadecanoic acid & $\mathrm{C}_{16} \mathrm{H}_{32} \mathrm{O}_{2}$ & 1.31 & 92 & 256 \\
\hline 12 & 22.51 & 11-Octadecenoic acid, methyl ester & $\mathrm{C}_{19} \mathrm{H}_{36} \mathrm{O}_{2}$ & 0.88 & 92 & 296 \\
\hline 13 & 23.66 & Oleic Acid & $\mathrm{C}_{18} \mathrm{H}_{34} \mathrm{O}_{2}$ & 5.82 & 94 & 282 \\
\hline 14 & 27.69 & Pentafluoropropionic acid, 2-ethylhexyl ester & $\mathrm{C}_{11} \mathrm{H}_{17} \mathrm{~F}_{5} \mathrm{O}_{2}$ & 2.15 & 78 & 276 \\
\hline
\end{tabular}

$+\mathrm{PN}=$ peak number, $\mathrm{RT}=$ retention Time in minutes, $\mathrm{MW}=$ Molecular weight in Dalton, $\mathrm{SI}=$ Similarity index in percentage to the mass peak in the NIST database.

\section{Conclusion}

In the present study fourteen chemical constituents have been identified from honey by Gas Chromatogram-Mass spectrometry (GC-MS) analyses and the Ngoundewre, Cameroon honey contains fourteen (14) chemical compounds with 2-Furancarboxaldehyde, 5-hydroxymethyl as the most abundant that could be bioactive.

\section{Recommendation}

Isolation of individual phytochemical constituents and subjecting them to biological activity may give fruitful results. However, due to the vast traditional used of honey; further studies will need to be undertaken to ascertain fully its bioactivity and it toxicity profile.

\section{Acknowledgements}

The authors wish to thanks Dr S.T. Mohammed of the Veterinary Teaching Hospital, Mr Gbenga of National Animal Production Institute Zaria and Mallam Gero of NARICT Laboratory Zaria for their technical assistance and logistic support.

\section{References}

[1] Codex Alimentarius Commission (2001a) Codex Standard for Honey, FAO, Rome. Alinorm 1: 19-26. 
[2] Codex Alimentarius Commission (2001b) Codex Standard 12, Revised Codex Standard for Honey, Standards and Standard Methods 11.

[3] James OO, Mesubi MA, Usman LA, Yeye SO, Ajanaku KO, et al. (2009) Physical characteristics of some honey samples from North-Central Nigeria. International Journal of Physical Sciences 4: $464-470$.

[4] White JW, Doner LW (1980) Honey composition and properties: Beekeeping in the United States. Agriculture Handbook No. 335, Revised October 82-91.

[5] Jeffrey AE, Echazarreta CM (1996) Medical uses of honey. Revista Biomedica 7: 43-49.

[6] Gheldof N, Engeseth NJ (2002) Antioxidant capacity of honeys from various floral sources based on the determination of oxygen radical absorbance capacity and inhibition of in vitro lipoprotein oxidation in human serum samples. J Agric Food Chem 50: 3050-3055.

[7] National Honey Board (2003) Honey: Health and Therapeutic Qualities. National Honey Board, Longman 28.

[8] Cantarelli MA, Pellerano RG, Marchevsky EJ, Camina (2008) Quality of honey from Argentina: study of chemical composition and trace elements. The Journal of the Argentine Chemical Society 96: 33-41.

[9] Ciappini MC, Gatti MB, Di Vito MV, Gattuso S, Gattuso M (2008) Characterization of different floral origins honey samples from Santa Fe (Argentina) by palynological, physicochemical and sensory data. Apiacta 43: 25-36.

[10] Omafuvbe BO, Akanbi OO. (2009) Microbiological and physico-chemical properties of some commercial Nigerian honey. African Journal of Microbiology Research 3: 891-896.

[11] Ebenezer IO, Olubenga MT (2010) Pollen characterization of honey samples from North Central Nigeria. Journal of Biological Sciences 10: 43-47.

[12] Ojeleye B (1999) Foundation of Beekeeping in the Tropics. CEBRAD Press Ltd., Ibadan 225.
[13] Ayoade JAA (1997) Beekeeping among the Tivs. The Nigerian Field 42: 31-36.

[14] Malaka SLO, Fasasi KA (2002) Beekeeping in Lagos and its Environs. Occasional Publication of Entomological Society of Nigeria 34: 92-97.

[15] Ojeleye B (1992) Foundation of Beekeeping in the Tropics. CEBRAD Press Ltd., Ibadan, 225.

[16] Subrahmanyam M., Archan Hemmady, Pawar S.G (2001). Antibacterial Activity Of Honey On Bacteria Isolated From Wounds. Annals of Burns and Fire Disasters - vol. XIV - n. I.

[17] Food Products Association, (2006). Emerging Chemical Contaminants Update. 1: (2), www.fpa-food.org/ Upload/library/071120068.pdf.

[18] White, J. W. Jr., (1980). Hydroxymethylfurfural content of honey as an indicator of its adulteration with invert sugars. Bee World, 61: 29-37.

[19] Omafuvbe BO, Akanbi OO (2009) Microbiological and physico-chemical properties of some commercial Nigerian honey. African Journal of Microbiology Research 3: 891-896.

[20] Adebiyi FM, Akpan I, Obianjuwa EI, Olaniyi HB (2004) Chemical/physical characterization of Nigerian honey. Pakistan Journal of Nutrition 3: 278-281.

[21] Adetuyi FO, Ibrahim TA, Ojei J, Ogundahunsi GA (2009). Total phenol, tocopherol and antibacterial quality of honey Apismellifera sold in Owo community, Ondo State, Nigeria. African Journal of Biotechnology 8: 1305-1309.

[22] Alissandrakis, E.; Tarantilis, P. A.; Harizans, P. C.; Polissons, M. (2007). Comparison of the volatile composition of thyme honeys from several origins in Greece. J. Agric. Food Chem., $55,8152-8157$.

[23] Castro-Várquez, LM.; Díaz-Maroto, M. C.; de Tores, C.; Pérez-Coello, M. S. (2010). Effects of geographical origins on the chemical and sensory characteristics of chestnut honeys. Food Res. Int. 43, 2335-2340. 